\title{
Histopathological Pattern of Spinal Tumor: Experience of 57 Cases in Bangladesh
}

\author{
Alam MS ${ }^{1}$, Haroon $\mathrm{K}^{2}$, Alamgir $\mathrm{MA}^{3}$, Uddin $\mathrm{KH}^{4}$, Ahmed $\mathrm{MF}^{5}$, Farzana $\mathrm{T}^{6}$, Md. Islam $\mathbf{N}^{7}$
}

Conflict of interest: There is no conflict of interest relevant to this paper to disclose.

Funding Agency: was not funded by any institute or any group.

Contribution of Authors: Principal Investigator and Manuscript preparation-

Data collection-

Scalp block with anaesthesia-

Editorial formatting-

Copyright: @2020bang.BJNS published by BSNS. This article is published under the creative commons CC-BY-NC license. This license permits use distribution (https://creativecommons. orgf/licences/by-nc/4-0/)reproduction in any medium, provided the original work is properly cited and is not used for commercial purposes.

Received: 16.01 .20

Accepted: 19.03 .20

\begin{abstract}
Background: Spinal cord tumors are presented with different histopathological pattern. Objective: The purpose of the present study was to see the different histopathological pattern of spinal tumor.
\end{abstract}

Methodology: This descriptive cross sectional study was conducted in the Department of Neurosurgery at National Institute of Neurosciences \& Hospital, Dhaka, Bangladesh from January 2016 to December 2019 for a period of 04 (Four) years. Patients presented with spinal tumor were selected as study population. After surgical removal the spinal tumor, tissue was sent for histopathological examination to the Department of Neuropathology of the same institute. Result: A total number of 57 spinal tumor cases were recruited for this study. The male and female ratio was 1.34:1. Out of 57 spinal tumor mostly were located in the intradural extramedullary (IDEM) which was 39(68.4\%) cases. Extradural and intramedullary were found in $7(12.3 \%)$ cases in each. Most of the spinal tumor were Schwannoma which was $28(49.1 \%)$ cases. Neurofibroma and meningioma were found in $6(10.5 \%)$ cases in each. Lipoma was found in 3(5.3\%) cases. Ependymoma was found in 4(7.0\%) cases.

Conclusion: In conclusion Schwannoma is the most common variant of spinal tumor detected among the study population.

Keywords: Histopathological pattern; spinal tumor;

Bang. J Neurosurgery 2020; 10(1): 27-32

\section{Introduction:}

Spinal cord tumors are uncommon neoplasms that, without treatment, can cause significant neurologic morbidity and mortality ${ }^{1}$. Primary spinal cord tumors constitute $2 \%$ to $4 \%$ of all central nervous system neoplasms and are characterized based on their location as intramedullary, intradural extramedullary, and extradural. Among intramedullary tumors, ependymomas are more common and often can be surgically resected. However, astrocytomas infiltrate the spinal cord and complete resection is difficult. Intradural extramedullary tumors include schwannomas, neurofibromas, and meningiomas and are usually amenable to surgical resection. Early recognition of the signs and symptoms related to primary spinal cord tumors facilitates timely discovery, treatment, potentially minimizes neurologic morbidity, and may improve outcome ${ }^{2}$. Spinal tumors are found most commonly in metastatic state. Up to $10.0 \%$ of patients who have symptomatic spine metastases can be treated by surgery ${ }^{3}$. The most common $(70.0 \%)$ sites for spine metastasis are thoracic and thoracolumbar spine, and lumbar spine and sacrum have more than $20.0 \%$ of metastatic lesions ${ }^{4}$. Cervical spine is a less frequent metastasis site.

The primary tumors of the spine are rare and the most of these lesions are asymptomatic ${ }^{5}$. Therefore, their real incidence is unknown. It is estimated that the

1. Md. Shafiul Alam, Associate Professor, Department of Gamma Knife, National Institute of Neurosciences \& Hospital.

2. Kaisar Haroon, Assistant Professor, Department of Clinical Neurosurgery, National Institute of Neurosciences \& Hospital.

3. Md. Abdullah Alamgir, Associate Professor, Department of Clinical Neurosurgery, National Institute of Neurosciences \& Hospital.

4. Kazi Hafiz Uddin, Assistant Professor, Department of Clinical Neurosurgery, National Institute of Neurosciences \& Hospital.

5. Md. Farhad Ahmed, Medical Officer, Department of Clinical Neurosurgery, National Institute of Neurosciences \& Hospital.

6. Tayseer Farzana, Consultant, Department of Radiology \& Imaging, Popular Diagnostic Center, Mirpur, Dhaka.

7. Md. Nowfel Islam, Professor, Department of Neuropathology, National Institute of Neurosciences \& Hospital.

Address of Correspondence: Dr. Md. Shafiul Alam, Associate Professor, Department of Gamma Knife, National Institute of Neurosciences and Hospital, Dhaka, Bangladesh. Tel: 01711567358, E mail: dr_chapal@hotmail.com 
incidence of haemangiomas which are accepted as the most common primary tumors of the spine, is between $11.0 \%$ and $14.0 \%$ cases $^{6}$. This ratio has been found to be dependent on lesions which have been detected incidentally in performing diagnostic procedures for another reasons. Proper diagnosis of these asymptomatic lesions which are seen commonly in the spine will prevent the advanced surgical procedures.

Except some primary tumors which tend to effect especially the spine, tumors originate from the skeleton system itself are not seen in the spine frequently ${ }^{7}$. Differential diagnosis of primary tumors of the spine from especially spinal infections is extremely important. Primary malignant tumors of the spine is the rarest tumor type in the spine. In all bone and soft tissue sarcomas, only $10.0 \%$ of them are related with the spine ${ }^{8}$. This present study was undertaken to see the different histopathological pattern of spinal tumor.

\section{Methodology:}

This descriptive cross sectional study was conducted in the Department of Neurosurgery at National Institute of Neurosciences \& Hospital, Dhaka, Bangladesh from January 2016 to November 2019 for a period of around 04 (four) years. Patients presented with spinal tumor at any age with both sexes were selected as study population. The demographics characteristics like age and gender were recorded among all the patients. Patients were examined by MRI for the detection of anatomical location of the tumor. The locations of involvement were divided into 5 levels which were cervical, thoracic, lumbar, sacrum and coccyx. The patients with hematologic and bone malignancy were excluded from this present study. The data were analyzed by using SPSS and reported with descriptive statistics. Categorical variables were expressed as frequency and percentage with the range of the data set. However, the continuous variables were expressed as mean with standard deviation when these data set were normally distributed. The present study was approved by local ethical committee.

\section{Result:}

A total number of 57 spinal tumor cases were recruited for this study. Most of the patients were in the age group of 40 to 60 years of age group which was $27(47.4 \%)$ cases followed by 20 to 40 years of age group and less than 20 years which were $22(38.6 \%)$ cases and $6(10.5 \%)$ cases respectively. Only 2 cases were in the age group of more than 60 years of age group. Male was predominant than female which was $33(57.9 \%)$ cases and $24(42.1 \%)$ cases respectively. The male and female ratio was 1.34:1 (Table 1).

Out of 57 spinal tumor mostly were located in the intradural extramedullary (IDEM) which was 39(68.4\%) cases. Extradural and intramedullary were found in $7(12.3 \%)$ cases in each. Only $4(7.0 \%)$ cases were Dumbbell (Table 2).

Most of the spinal tumor were Schwannoma which was $28(49.1 \%)$ cases. Neurofibroma and meningioma were found in 6(10.5\%) cases in each. Lipoma was found in $3(5.3 \%)$ cases. Ependymoma was found in $4(7.0 \%)$ cases. However, different variants were found in 10 cases which were abscess (1), arachnoid cyst (2), astrocytoma (1), haemangioblastoma (1), haemangioma (1), hamartoma (1), malignant nerve sheath tumour (1) and paraganglioma (1) (Table 3).

Table-I

Age and Gender Distribution of Study Population ( $n=57)$

\begin{tabular}{|c|c|c|c|c|}
\hline \multirow[t]{2}{*}{ Age Group } & \multicolumn{2}{|c|}{ Gender } & \multirow[t]{2}{*}{ Total } & \multirow[t]{2}{*}{ P Value } \\
\hline & Male & Female & & \\
\hline Less than 20 Years & $4(12.1 \%)$ & $2(8.3 \%)$ & $6(10.5 \%)$ & 0.523 \\
\hline 20 to 40 Years & $15(45.5 \%)$ & $7(29.2 \%)$ & $22(38.6 \%)$ & \\
\hline 40 to 60 Years & $13(39.4 \%)$ & $14(58.3 \%)$ & $27(47.4 \%)$ & \\
\hline More Than 60 Years & $1(3.0 \%)$ & $1(4.2 \%)$ & $2(3.5 \%)$ & \\
\hline Total & $33(100.0 \%)$ & $24(100.0 \%)$ & $57(100.0 \%)$ & \\
\hline
\end{tabular}


Table-II

Distribution of Spinal Tumor according to Location $(n=57)$

\begin{tabular}{lcc}
\hline Location & Frequency & Percent \\
\hline Intradural Extramedullary & 39 & 68.4 \\
Extradural & 7 & 12.3 \\
Intramedullary & 7 & 12.3 \\
Dumbbell & 4 & 7.0 \\
\hline Total & 57 & 100.0 \\
\hline
\end{tabular}

Table-III

Distribution of Spinal Tumor according to Histopathological Pattern ( $n=57)$

\begin{tabular}{lcc}
\hline Types & Frequency & Percent \\
\hline Schwannoma & 28 & 49.1 \\
Neurofibroma & 6 & 10.5 \\
Meningioma & 6 & 10.5 \\
Lipoma & 3 & 5.3 \\
Ependymoma & 4 & 7.0 \\
Others & 10 & 17.5 \\
\hline Total & 57 & 100.0 \\
\hline
\end{tabular}

Fig.-1: Intradural Extramedullary Schwannoma
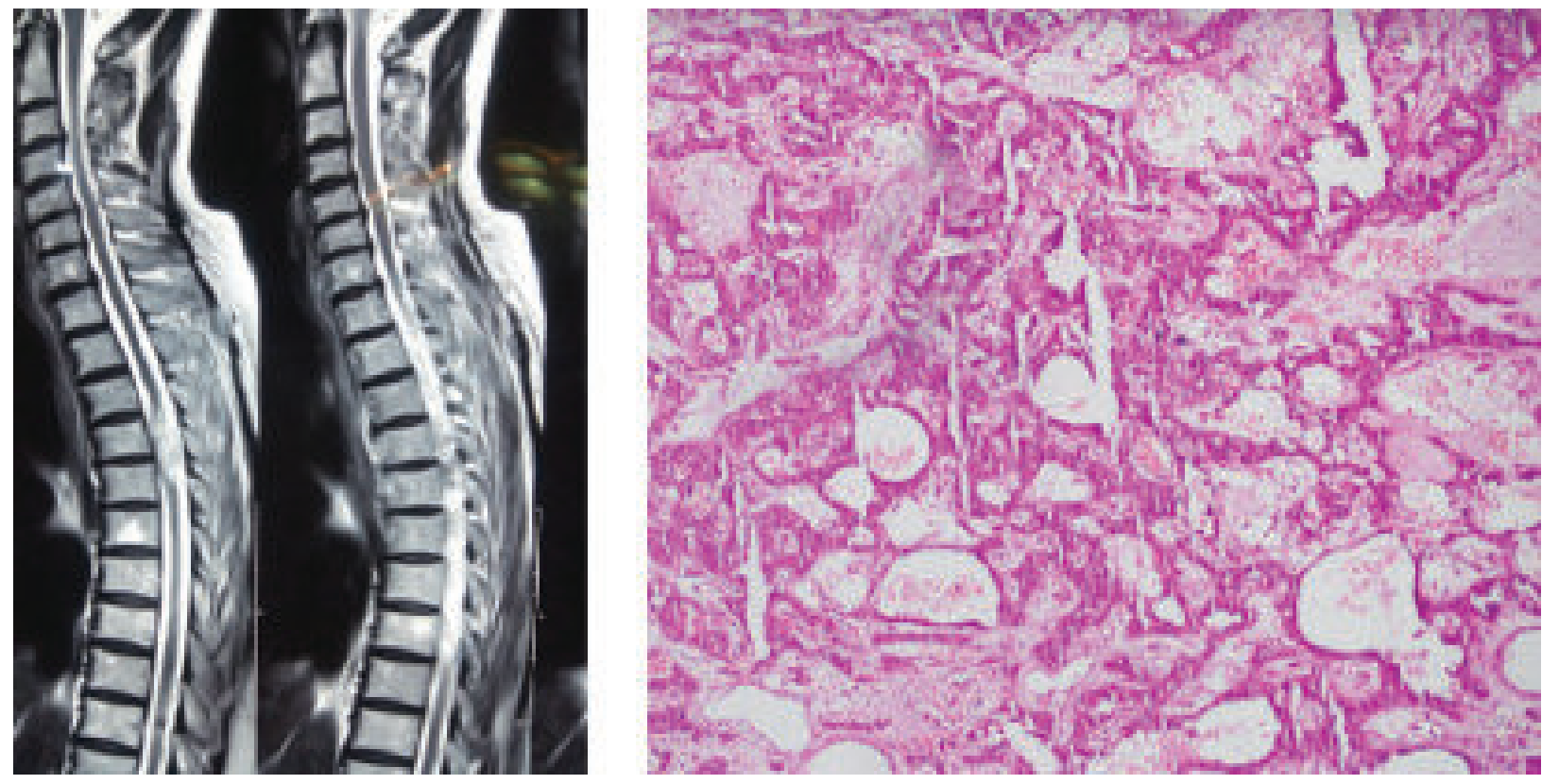

Fig.-2: Intradural Extramedullary Meningioma 

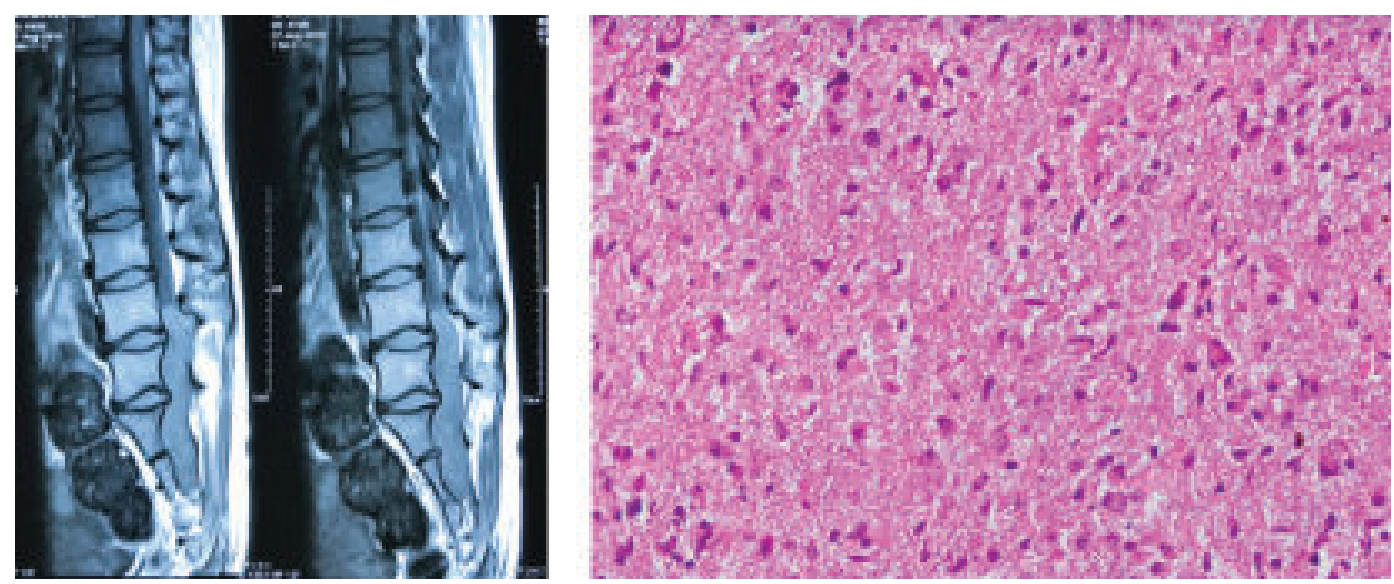

Fig.-3: Intradural Extramedullary Myxopapillary Ependymoma
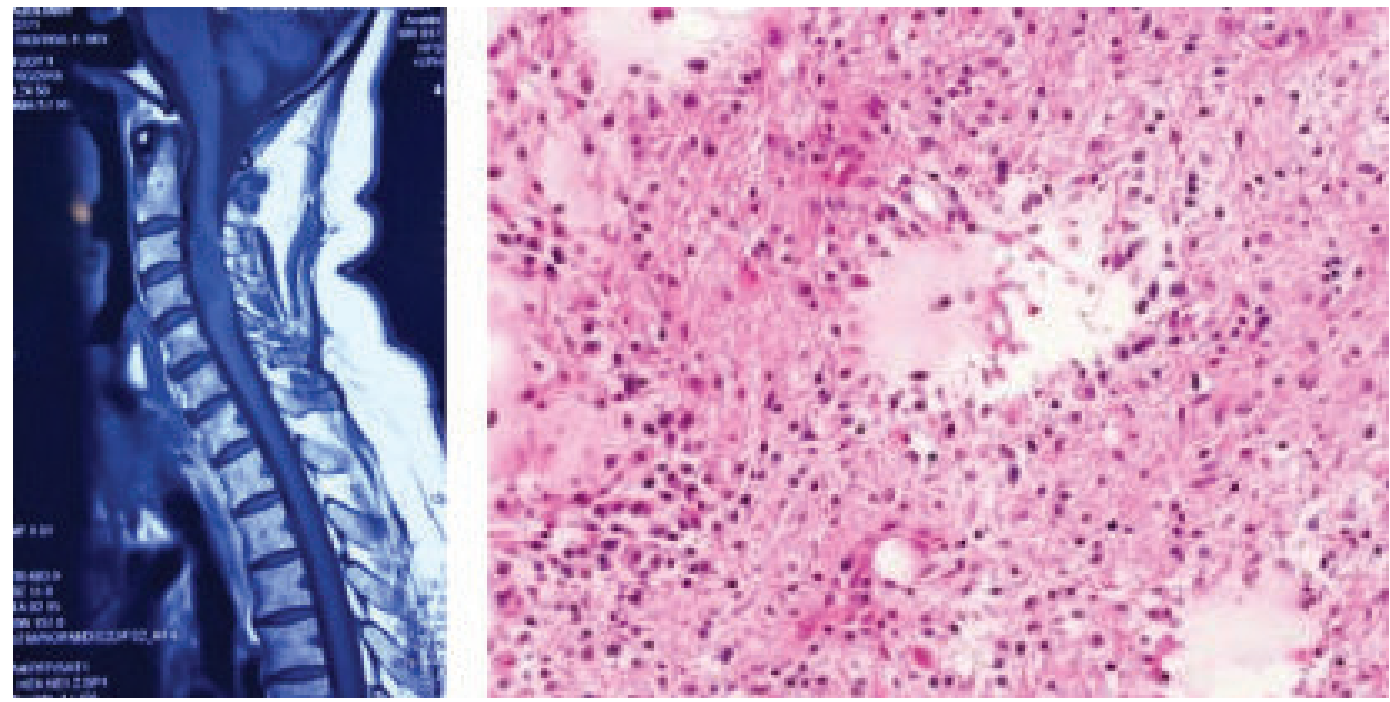

Fig.-4: Intramedullary Astrocytoma
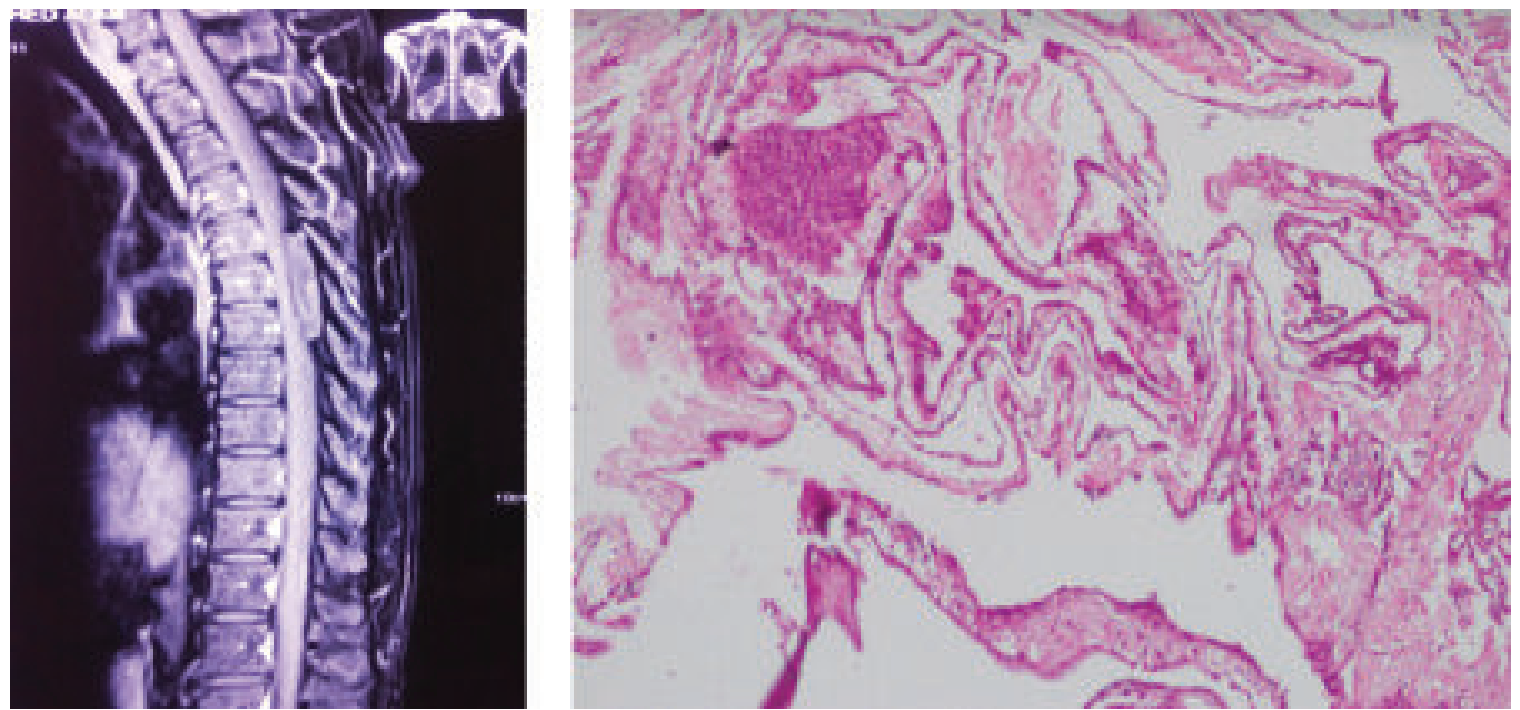

Fig.-5: Extradural Arachnoid Cyst 


\section{Discussion:}

The incidence patterns demonstrates that pathologically confirmed primary spinal tumor have been increasing over the last 30 years, primarily due to the significant increased incidence of ependymomas $^{8}$. The incidence of grade I astrocytoma has also appeared to trend upwards, while the incidence of astrocytoma NOS trended downward and the incidence of other subtypes does not change appreciably during this time period ${ }^{9}$. While no percentage change statistics could be calculated because of small sample sizes, an increase in the incidence of astrocytoma has been observed by others.

Out of 57 spinal tumor mostly are located in the intradural extramedullary (IDEM) which was $39(68.4 \%)$ cases. Extradural and intramedullary were found in $7(12.3 \%)$ cases in each. Only $4(7.0 \%)$ cases were Dumbbell. Similar to the present study result Hirano et $\mathrm{l}^{10}{ }^{10}$ have reported that $18.3 \%$ patients are presented with intramedullary tumors followed by $54.7 \%$ with intradural extramedullary tumors, $4.0 \%$ with epidural tumors and $22.9 \%$ with dumbbell tumors.

In this present study, most of the spinal tumor were Schwannoma which was $28(49.1 \%)$ cases. Neurofibroma and meningioma were found in $6(10.5 \%)$ cases in each. Lipoma was found in 3(5.3\%) cases. Ependymoma was found in $4(7.0 \%)$ cases. However, different variants were found in 10 cases which were abscess, arachnoid cyst, astrocytoma, haemangioblastoma, haemangioma, hamartoma, malignant nerve sheath tumor and paraganglioma. Therefore, it is very clear that the spinal origin of tumor is the most common variant. Similarly, Duong et al ${ }^{11}$ have stated that the most common site of all primary spinal tumors is the spinal cord $(60.5 \%)$, followed by spinal meninges $(36.0 \%)$, and then cauda equina $(3.5 \%)$. This result is similar to a study by Schellinger et al $^{1}$ who have reported spinal cord in $70.0 \%$, spinal meninges in $26.0 \%$, cauda equine in $4.0 \%$. However, another study has been found equal proportions of spinal cord and spinal meninges ${ }^{12}$. Hirano et al ${ }^{10}$ have reported that ependymomas and schwannomas are commonly found in middle-aged patients, while meningiomas are found in middle-aged and older patients. These tumors are predominant in this present study. Still other reports indicate that the most common primary spinal cord tumor in patients older than 60 years is meningioma, with a higher incidence than schwannomas ${ }^{13}$.
The biological explanation for the observed increased incidence of primary malignant spinal gliomas, specifically ependymomas, remains unclear ${ }^{14}$. MRI of the spine is currently the diagnostic study of choice and almost all intrinsic malignant spinal cord tumors enhance with gadolinium. The advent of MRI imaging may have led to increased detection and it is possible that the observed increased incidence merely reflects the increased sensitivity of the diagnostic technologies resulting in increased frequency of identification of these neoplasms and a related increased tendency towards surgical diagnosis and intervention rather than a true increased incidence ${ }^{9}$. However, there are no sharp inflections in incidence with the analysis, which is expected with an acute advancement in diagnostic technology. Histologic criteria, which are somewhat qualitative and subjective, have also evolved over time and are dependent on pathologist experience and preference, which could also have influenced incidence rates.

\section{Conclusion:}

In conclusion Schwannoma is the most common variant of spinal tumor detected among the study population. Neurofibroma and meningioma are also found and these are the second highest histopathological variant of spinal tumor. Furthermore, most of the tumor are located in the intradural extramedullary (IDEM) region. However, Extradural and intramedullary are also found. Further large scale study should be conducted to see the real scenario of Bangladesh.

\section{References:}

1. Mechtler, Laszlo L., and Kaveer Nandigam. "Spinal cord tumors: new views and future directions." Neurologic clinics 31.1 (2013): 241-268.

2. Chamberlain, Marc C., and Trent L. Tredway. "Adult primary intradural spinal cord tumors: a review." Current neurology and neuroscience reports 11.3 (2011): 320-328.

3. Henson JW. Spinal cord gliomas. Curr Opin Neurol. 2001;14:679-682

4. Elia-Pasquet $S$, Provost D, Jaffre A, Loiseau H, Vital A, Kantor $G$, et al. Incidence of central nervous system tumors in Gironde, France. Neuroepidemiology. 2004; 23:110-117

5. Nakamura M, Toyama Y. Diagnosis and Treatment for spinal cord tumors. J Japan Spine Res Soc. 2005;16:472-486

6. Klekamp J, Samii M. Surgery of spinal tumors. Heidelberg: Springer; 2006

7. Shrivastava RK, Epstein FJ, Perin NI, Post KD, Jallo GI. Intramedullary spinal cord tumors in patients older than 50 
years of age: management and outcome analysis. $\mathrm{J}$ Neurosurg Spine. 2005;2:249-255

8. Lewandrowski KU, Anderson ME, McLain RF. Tumors of the Spine. In: Herkowitz HN, Garfin SR, Eismont FJ, Bell GR, Balderston RA, et al., editors. Philadelphia: Elsevier Saunders; 2011. pp. 1480-1512

9. Choi D, Crockard A, Bunger C, Harms J, Kawahara N, Mazel C, Melcher R, Tomita K. Review of metastatic spine tumour classification and indications for surgery: the consensus statement of the Global Spine Tumour Study Group. Eur Spine J. 2010;19:215-222

10. Hirano K, Imagama S, Sato K, Kato F, Yukawa Y, Yoshihara H, Kamiya M, Deguchi M, Kanemura T, Matsubara Y, Inoh H. Primary spinal cord tumors: review of 678 surgically treated patients in Japan. A multicenter study. European spine journal. 2012 Oct 1;21(10):2019-26.
11. Duong LM, McCarthy BJ, McLendon RE, Dolecek TA, Kruchko C, Douglas LL, Ajani UA. Descriptive epidemiology of malignant and nonmalignant primary spinal cord, spinal meninges, and cauda equina tumors, United States, 2004 2007. Cancer. 2012 Sep 1;118(17):4220-7.

12. Johannesen TB, Angell-Andersen E, Tretli S, Langmark F, Lote $\mathrm{K}$. Trends in incidence of brain and central nervous system tumors in Norway, 19701999. Neuroepidemiology. 2004;23:101-109

13. Aboulaflia AJ, Levine AM. Musculoskeletal and Metastatic Tumors. In: Fardon DF, Garfin SR, et al., editors. OKU: Spine 2, Rosemont. American Academy of Orthopaedic Surgeons; 2002. pp. 411-431

14. Deol GS, Haydol R, Phillips FM. Tumors of the Spine. In: Vaccaro AR. OKU 8, Rosemont. American Academy of Orthopaedic Surgeons; 2005. pp. 587-599 